\title{
A Bridge Too Far? An Integrative Framework Linking Classical Protist Taxonomy and Metabarcoding in Lower Termites
}

\author{
Sónia Duarte ${ }^{1,2}$, Lina Nunes ${ }^{1}$, Paulo A. V. Borges ${ }^{2}$ and Tania Nobre ${ }^{3 *}$ \\ ${ }^{1}$ National Laboratory for Civil Engineering, Department of Structures, Lisbon, Portugal, ${ }^{2}$ Evolution and Environmental \\ Changes/Azorean Biodiversity Group, cE3c-Center for Ecology, Departamento de Ciências e Engenharia do Ambiente, \\ Universidade dos Açores, Açores, Portugal, ${ }^{3}$ Laboratório de Entomologia, Instituto de Ciências Agrárias e Ambientais \\ Mediterrânicas, Universidade de Évora, Évora, Portugal
}

Keywords: termite, protists, symbionts, metabarcoding, taxonomy

\section{OPEN ACCESS}

Edited by:

David William Waite,

University of Auckland, New Zealand

Reviewed by:

Morten Schiøtt,

University of Copenhagen, Denmark

Vincent Hervé,

Max-Planck-Institut für Terrestrische

Mikrobiologie, Germany

*Correspondence:

Tania Nobre

tnobre@uevora.pt

Specialty section:

This article was submitted to

Microbial Symbioses,

a section of the journal

Frontiers in Microbiology

Received: 27 July 2018 Accepted: 12 October 2018 Published: 08 November 2018

Citation:

Duarte S, Nunes L, Borges PAV and Nobre T (2018) A Bridge Too Far? An Integrative Framework Linking

Classical Protist Taxonomy and

Metabarcoding in Lower Termites.

Front. Microbiol. 9:2620.

doi: 10.3389/fmich.2018.02620
The concept of individuality has changed, since symbiosis is now accepted as being widespread and not an exception. Symbiotic microorganisms are not only crucial for the evolutionary and ecological success of many organisms (take land plants as an iconic example) but can also be key to many current human caused challenges (biomass degradation and bioenergy, for example). Nowadays, many tools are available allowing to study the hidden microbiological world, but we should not neglect that, for certain aims, researchers do need to incorporate these new technologies with less appealing and more classical approaches in an integrative framework. Using the example of lower termites' symbiosis with their protists, we intend to stimulate debate and to encourage cooperation between researchers toward high quality "big data" that can bring us closer to the pursued answers.

\section{THE "OMICS ERA" IN THE MICROBIAL ENDOSYMBIOSIS WORLD}

The fast development of molecular techniques, especially the high-throughput sequencing methods (HTS) during the past years, has made the in-situ detection of microorganisms feasible. The perception that an organism is never alone is well established and fueled the desire to unveil the hidden world of the microbial symbiosis.

In this new "omics era" a new set of tools and techniques allowing the study of not yet cultivated (or difficult to cultivate) symbionts are available. The advances in DNA sequencing technology and the use of the $16 \mathrm{~S}$ rRNA gene as a taxonomic marker have enabled the genetic identification of bacteria, being nowadays a well-established approach (e.g., Otani et al., 2014; Bin et al., 2018). For symbiotic fungi metabarcoding, approaches targeting the mycobiome of plants (e.g., mycorrhizal fungus) or invertebrates (e.g., pathogenic fungus) have been widely employed and both primer sets and comparative databases are available and growing (for a review see Cuadros-Orellana et al., 2013). For other groups, like the protists, the approaches are less well established.

In the microbial endosymbiosis world, the interactions may have several roles, from reproductive to digestive or even protective. A classic digestive endosymbiosis is the one between termites and their symbionts, and much of the research has been focused on the microbial symbiosis that aids the wood digestion process. The symbiotic association between termites and their hindgut symbionts has advantages for both, since the termites obtain energy as a result of the cooperative lignocellulose digestion, and hindgut symbionts have shelter, protection and food, supplied by the termite host (e.g., Brune, 2013; Tamschick and Radek, 2013). In addition to the synergistic digestive collaboration, symbionts of lower termites may also play a protective role against pathogens (see Peterson and Scharf, 2016). 


\section{SYMBIOTIC FLAGELLATE PROTISTS: THE CASE STUDY OF LOWER TERMITES}

Flagellate protists inhabit the lower termite's gut, an ancestral trait shared with wood-feeding cockroaches (e.g., Lo and Eggleton, 2011; Brune and Dietrich, 2015). The gut protists belong to either the phylum Parabasalia or the order Oxymonadida (phylum Preaxostyla). Termite guts harbor a great diversity of protist species.

The characterization of flagellate protists living inside termites is a challenging wide field of research, which initially relied solely on the morphological characterization of the cells (Leidy, 1877; Kudo, 1939; Grassé, 1952), and nowadays should ideally rely on an integrative taxonomic approach, using evidence from morphology and molecular data to delimit protist species (e.g., Carpenter et al., 2009; Harper et al., 2009; James et al., 2012) and contributing to solve the Linnean shortfall (Cardoso et al., 2011; Hortal et al., 2015). However, the identification of flagellate protists symbiotic to termites is highly impaired by the difficult task of maintaining a laboratory rearing of these organisms: the intricate physical and chemical conditions existing inside the termite hindgut (particularly, gradients of oxygen, hydrogen, and $\mathrm{pH}$ ), powered by the protists and bacterial symbionts activities, are almost impossible to reproduce in a laboratory environment, and are of utmost importance for the survival of the different species of flagellate protists. Therefore, most methods for the analysis of these symbionts are limited to the direct observation of the hindgut of freshly killed and healthy termites, followed by the isolation of each cell from the microbiome and its morphologic description. Nowadays, this is clearly not enough.

The morphologically described species, which associate to termites, amount to more than 400 parabasalids and 70 oxymonads (reviewed in Ohkuma and Brune, 2011). With the technological advances, some single cell sequences (from protists manually isolated under microscopy; Figure 1) are becoming available (Supplementary Table 1). However, many taxonomically important species have not yet been subjected to any molecular study. The in-situ detection of flagellate protists, through metabarcoding approaches is available but requires database data for bioinformatics comparison to obtain organisms' identification and biological role inference. Other studies, such as meta-transcriptomics are actually overcoming the drawback of the need of protists individual identification and focus on protists community of symbionts functional role by transcript inference (e.g., on lignocellulolytic process; Scharf et al., 2011; Xie et al., 2012; Raychoudhury et al., 2013, Liu et al., 2016). Even if the use of differential gene expression analyses for understanding community responses to specific conditions does overcome the need of flagellate protists species knowledge, these analyses do not contribute to our understanding of the protistan diversity nor to the identification of a given species (only community information) needed for a specific biotechnological purpose.

Furthermore, we often see no gradation in the information available, hindering the integration of the knowledge at its different scales. In short, and with some important exceptions
(Supplementary Table 1), we went from single cells described morphologically to community approaches focusing on processes and responses. The relevance of this data is unarguable and could drastically increase if the "distance" between morphotypes and the operational taxonomic units or OTUs responses could be bridged.

\section{BOTTLENECKS TO THE WORKFLOW, FROM GUTS TO FLAGELLATE PROTISTS SEQUENCES}

Basically, an HTS approach to termite's protist gut community entails the sequence analysis of target amplicons, PCR amplified from DNA arising from the protist genomes directly extracted from the gut. The targets for such analyses are of course genes of taxonomic interest. The sequenced amplicons are clustered, and the representative sequences (OTUs) are compared to reference databases.

In this workflow, from guts to flagellate protists sequences, a number of bottlenecks are not yet possible to fully overcome: (a) availability of reference data (library), (b) efficient primers covering the diversity of preaxostyla and parabasalia, and (c) the lack of knowledge on the proper clustering threshold so that oxymonad and parabasalid sequences OTU do reflect a species; no doubt a consequence of the low level of knowledge on these groups of organisms.

Recently, Jasso-Selles et al. (2017) looked into the hindgut community of Heterotermes aureus Snyder using an integrative approach that included three techniques: (i) light microscopy, (ii) single cell isolation, and (iii) high throughput amplicon sequencing. This study is an example of bridging classical morphological studies with HTP approach, describing four new parabasalids and designed 18S rRNA gene parabasalids primers to access population-level differences in hindgut community composition. The reduced geographical range of $H$. aureus might determine its simple microbial community when compared to other Rhinotermitidae species. The characterization of the community of parabasalids symbiotic to termites belonging to Zootermopsis genus and the investigation of the possible coevolutionary mechanisms influencing their diversity has also been recently done following the same integrative approach (Taerum et al., 2018). Reticulitermes species, however, harbor flagellate protists from the phylum Parabasalia but also from the order Oxymonadida (phylum Preaxostyla) and the number of protists identified in a single Reticulitermes species vary per study (Lo Pinto et al., 2016 and references therein), caste and season (e.g., Benjamino and Graf, 2016) but reports of more than 15 species (or morphotypes) are accredited (Leidy, 1877; Mello, 1920; Cleveland, 1923; Bloodgood et al., 1974; Breznak and Pankratz, 1977; Mauldin, 1977; Mauldin et al., 1981; Lelis, 1992; Cook and Gold, 1998; Stingl and Brune, 2003; Stingl et al., 2005; Brugerolle, 2006; Brugerolle and Bordereau, 2006; Lewis and Forschler, 2006; Hu, 2008; Hu et al., 2011; Tamschick and Radek, 2013; and references therein: Kudo, 1939; Ghidini, 1942; Yamin, 1979; Grassé, 1982). In Reticulitermes at least, an HTS approach is hampered by the lack of universal primers and the absence of 


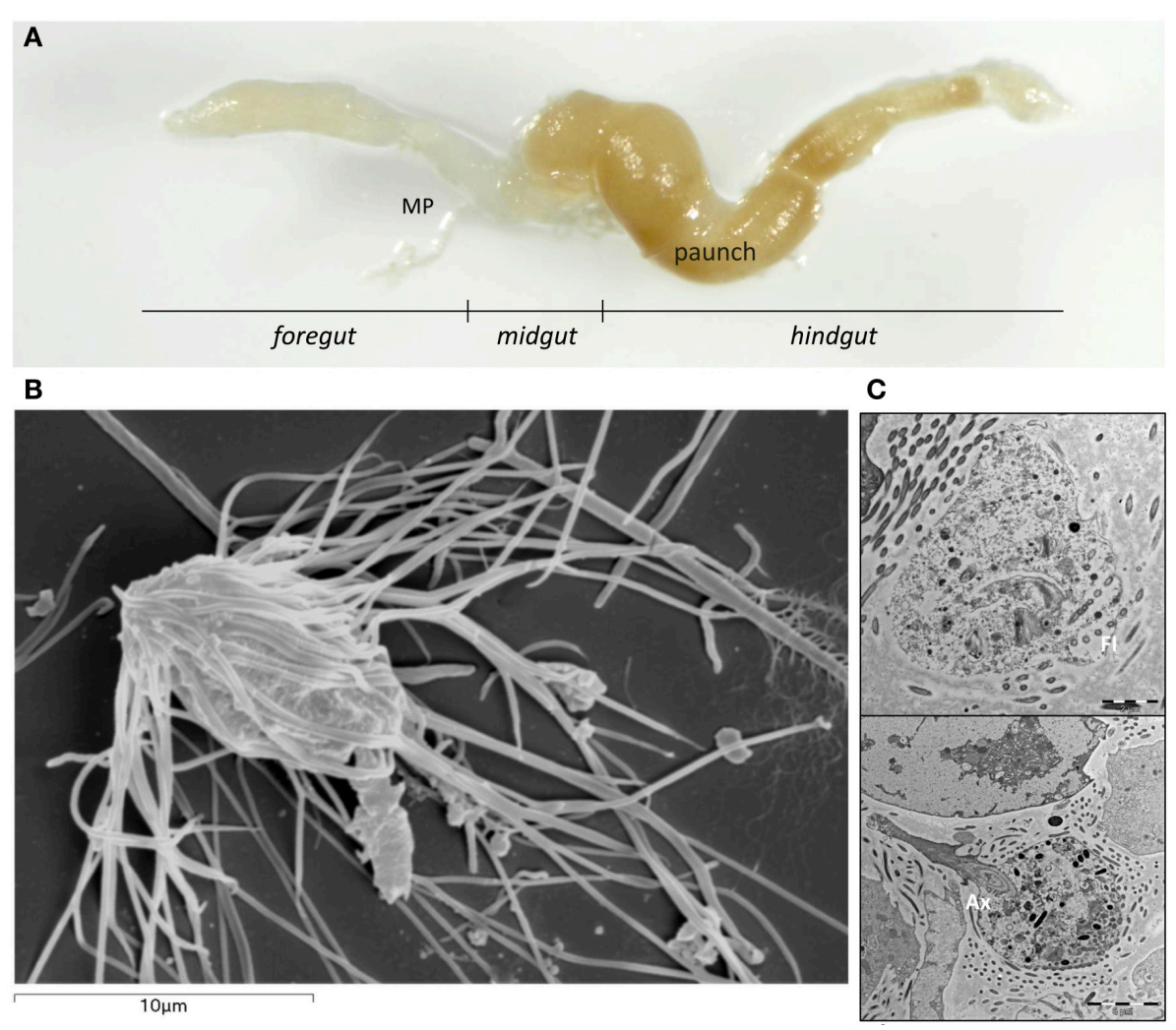

FIGURE 1 | (A) Extracted gut with different parts of the subterranean termite Reticulitermes grassei Clément gut: Foregut; Midgut, including the Malpighian tubules (MP) at the posterior end of the midgut; Hindgut. (B) Scanning electron micrograph of Microjoenia hexamitoides. (C) Longitudinal section of Microjoenia hexamitoides showing flagellar lines (Fl) around the anterior zone of the cell and posteriorly protruding axostyle (Ax).

a reference database, including $18 \mathrm{~S}$ rRNA gene sequences and species/morphotype linkage.

\section{BRIDGING THE GAP: SINGLE CELL STUDIES COMBINING MICROSCOPY}

To bridge the created gap knowledge an integrative approach should be followed, merging classical microscopy methods with single cell isolation and molecular identification. Efforts should move toward an "ID card" for every flagellate protist symbiotic of termites, where morphology, including a diagnose image and $18 \mathrm{~S}$ rRNA gene signature should be present, together with a (tentative) taxonomy. This single locus barcoding strategy should then be followed by a more ambitious strategy to produce multi-locus protist phylogenies by sequencing several marker genes, or ideally by sequencing whole protist genomes in order to move toward performing phylogenomics of termite gut flagellates. Other information, such as morphological and/or motility characteristics, host species, geographical origin and habitat identification of the sample would be reported as extra information. If possible, molecular data on the host should be provided allowing its phylogenetic identification, and progress toward hypotheses testing, such as host-symbiont specificity and co-evolution. The tools are available; we just need to join forces! This would be the creation of a common database, at single cell level, which would enable the widespread use of meaningful and fruitful HTS approaches. Data would also be made available on all relevant databases, such as Barcode of Life Database (BOLD, for the host-http://www. boldsystems.org/; Ratnasingham and Hebert, 2007), The Protist Ribosomal Reference database (PR2-https://github.com/vaulot/ pr2database; Guillou et al., 2013), SILVA ribosomal RNA database (SILVA-https://www.arb-silva.de/; Quast et al., 2013) and Eukaryotic Reference Database (EukRef-http://eukref.org/ databases/; Campo et al., 2018). Describing and understanding the roles of each different species could help linking termite biology with termite control. This would also directly impact in diverse biotechnological niches, including the discovery of organisms producing lignocellulases and other enzymes -with applications in a variety of biomass, industrial, and processing technologies.

This approach will not only contribute to surpass the Linnean shortfall but will also contribute to a better understanding of the ecological and evolutionary characteristics of symbiotic microorganisms. In a near future it will be possible to document species relationships and describe the detailed networks between most symbiotic microorganisms and their hosts. More importantly this new data will populate important biodiversity databases such as the Global Biodiversity Information Facility 
(http://www.gbif.org/), the Catalog of Life or the Encyclopedia of Life (http://www.eol.org) and will provide invaluable resources for the advancement of ecological research and biotechnology.

\section{AUTHOR CONTRIBUTIONS}

TN and LN conceived the idea and designed the structure of the manuscript. SD, LN, and TN drafted the manuscript, figure and supplemental material table. SD, LN, PB and TN have critically read, corrected, and approved the final version of the manuscript and agree with the opinions expressed here.

\section{FUNDING}

SD's work was supported by Portuguese National Funds through Fundação para a Ciência e a Tecnologia (FCT) Ph.D. grant

\section{REFERENCES}

Benjamino, J., and Graf, J. (2016). Characterization of the core and caste-specific microbiota in the termite, Reticulitermes flavipes. Front. Microbiol. 7:171. doi: $10.3389 /$ fmicb.2016.00171

Bin, J., Qin, H., Guo, S. D., Chen, W., Zhang, X. C., and Liang, J. C. (2018). Bacterial communities of four adjacent fresh lakes at different trophic status. Ecotoxicol. Environ. Saf. 157, 388-394. doi: 10.1016/j.ecoenv.2018.03.086

Bloodgood, R. A., Miller, K. R., Fitzharris, T., and Mcintosh, J. R. (1974). The ultrastructure of Pyrsonympha and its associated microorganisms. J. Morphol. 143, 77-105. doi: 10.1002/jmor.1051430104

Breznak, J., and Pankratz, S. (1977). In situ morphology of the gut microbiota of wood-eating termites Reticulitermes flavipes and Coptotermes formosanus. Appl. Environ. Microbiol. 33, 406-426.

Brugerolle, G. (2006). Comparative cytological study of four species in the genera Holomastigotes and Uteronympha n. comb. (Holomastigotidae, Parabasalia), symbiotic flagellates of termites. J. Eukaryot. Microbiol. 53, 246-259. doi: 10.1111/j.1550-7408.2006.00107.x

Brugerolle, G., and Bordereau, C. (2006). Immunological and ultrastructural characterization of spirotrichonymphid flagellates from Reticulitermes grassei and R. flavipes (syn. R. santonensis), with special reference to Spirotrichonympha, Spironympha and Microjoenia. Org. Divers. Evol. 6, 109-123. doi: 10.1016/j.ode.2005. 07.004

Brune, A. (2013). "Symbiotic associations between termites and prokaryotes," in The Prokaryotes-Prokaryotic Biology and Symbiotic Associations, eds E. Rosenberg, E. DeLong, E. Stackebrandt, S. Lory, and F. Thompson (Berlin; Heidelberg: Springer-Verlag), 545-577.

Brune, A., and Dietrich, C. (2015). The gut microbiota of termites: digesting the diversity in the light of ecology and evolution. Annu. Rev. Microbiol. 69, 145-166. doi: 10.1146/annurev-micro-092412-155715

Campo, J., Kolisko, M., Boscaro, V., Santoferrara, L. F., Guillou, L., Simpson, A., et al. (2018). EukRef: phylogenetic curation of ribosomal RNA to enhance understanding of eukaryotic diversity and distribution. PLoS Biol. 16:e2005849. doi: 10.1371/journal.pbio.2005849

Cardoso, P., Erwin, T. L., Borges, P. A. V., and New, T. R. (2011). The seven impediments in invertebrate conservation and how to overcome them. Biol. Cons. 144, 2647-2655. doi: 10.1016/j.biocon.2011. 07.024

Carpenter, K. J., Chow, L., and Keeling, P. J. (2009). Morphology, phylogeny, and diversity of Trichonympha (Parabasalia: Hypermastigida) of the wood-feeding cockroach Cryptocercus punctulatus. J. Eukariot. Microbiol. 56, 305-313. doi: $10.1111 /$ j.1550-7408.2009.00406.x

Cleveland, L. (1923). Symbiosis between termites and their intestinal protozoa. Proc. Natl. Acad. Sci. U.S.A. 9, 424-428. doi: 10.1073/pnas.9.12.424
SFRH/BD/84920/2012. This manuscript was partly financed by Portuguese National Funds, through FCT, within the project UID/BIA/00329/2013. The work was also carried out within LNEC's project CONSTBIO.

\section{ACKNOWLEDGMENTS}

We would like to acknowledge the help of Telmo Nunes in the SEM image acquisition and the valuable suggestions of the reviewers.

\section{SUPPLEMENTARY MATERIAL}

The Supplementary Material for this article can be found online at: https://www.frontiersin.org/articles/10.3389/fmicb. 2018.02620/full\#supplementary-material

Cook, T. J., and Gold, R. E. (1998). Organization of the symbiotic flagellate community in three castes of the eastern subterranean termite, Reticulitermes flavipes (Isoptera: Rhinotermitidae). Sociobiology 1, 25-39.

Cuadros-Orellana, S., Leite, L. R., Smith, A., Medeiros, J. D., Badotti, F., Fonseca, P. L. C., et al. (2013). Assessment of fungal diversity in the environment using metagenomics: a decade in review. Fungal Genomics Biol. 3:110. doi: 10.4172/2165-8056.1000110

Ghidini, G. M. (1942). Studi sulle termiti: $11^{\circ}$ - Le Trichonympha di Reticulitermes lucifugus Rossi. Rivista di Biol. Coloniale 5, 19-40.

Grassé, P. P. (1952). “Ordre des Joeniides nov. (Joeniidea nov. ordo.). Famille des Rhizonymphidae Grassé et Hollande, 1951. Ordre des Lophomonadines nov. Lophomonadina (n. nov.). Famille des Microjoeniidae nov. Ordre des trychonymphines nov. (Spirotrichonymphina nov.)," in Traité de Zoologie, Vol. 1. ed P. P. Grassé (Paris: Masson et Cie), 836-942.

Grassé, P. P. (1982). Termitologia. Anatomie, Physiologie, Biologie, Systématique des termites. Tome I: Anatomie, Physiologie, Reproduction. Paris: Fondation Singer-Polignac, Masson.

Guillou, L., Bachar, D., Audic, S., Bass, D., Berney, C., Bittner, L., et al. (2013). The Protist Ribosomal Reference database (PR2): A catalog of unicellular eukaryote Small Sub-Unit rRNA sequences with curated taxonomy. Nucleic Acids Res. 41, 597-604. doi: 10.1093/nar/gks1160

Harper, J. T., Gile, G. H., James, E. R., Carpenter, K. J., and Keeling, P. J. (2009). The inadequacy of morphology for species and genus delineation in microbial eukaryotes: an example from the parabasalian termite symbiont Coronympha. PLoS ONE 4:e6577. doi: 10.1371/journal.pone.0006577

Hortal, J., de Bello, F., Diniz-Filho, J. A. F., Lewinsohn, T. M., Lobo, J. M., and Ladle, R. J. (2015). Seven shortfalls that beset large-scale knowledge of biodiversity. Annu. Rev. Ecol. Evol. Syst. 46, 523-549. doi: 10.1146/annurev-ecolsys-112414-054400

Hu, X. P. (2008). "Starvation-associated mortality, cannibalism, body weight, and intestinal symbiotic protist profile of Reticulitermes flavipes (Isoptera: Rhinotermitidae)," in Proceedings of the Sixth International Conference on Urban Pests eds W. H. Robinson and D. Bajomi (Budapest: OOK-Press Kft.), 365-371.

Hu, X. P., Song, D., and Gao, X. (2011). Biological changes in the Eastern subterranean termite, Reticulitermes flavipes (Isoptera, Rhinotermitidae) and its protozoa profile following starvation. Insectes Soc. 58, 39-45. doi: $10.1007 /$ s00040-010-0114-1

James, E. R., Tai, V., Scheffrahn, R. H., and Keeling, P. J. (2012). Trichonympha burlesquei n. sp. from Reticulitermes virginicus and evidence against a cosmopolitan distribution of Trichonympha agilis in many termite hosts. Int. J. Syst. Evol. Microbiol. 63, 3873-3876. doi: 10.1099/ijs.0.054874-0

Jasso-Selles, D. E., Martini, F. D., Freeman, K. D., Garcia, M. D., Merrell, T. L., Scheffrahn, R. H., et al. (2017). The parabasalid symbiont community of Heterotermes aureus: molecular and morphological characterization of four 
new species and reestablishment of the genus Cononympha. Eur. J. Protistol. 61, 48-63. doi: 10.1016/j.ejop.2017.09.001

Kudo, R. R. (1939). Protozoology, 5th Edn. Springfield, IL: Charles C. Thomas Publisher.

Leidy, J. (1877). On intestinal parasites of Termes flavipes. Proc. Acad. Nat. Sci. Phila. 29, 146-149.

Lelis, A. (1992). The loss of intestinal flagellates in termites exposed to the juvenile hormone analogue (JHA)-methoprene. Mater. Organ. 27, 172-178.

Lewis, J. L., and Forschler, B. T. (2006). A nondichotomous key to protist species identification of Reticulitermes (Isoptera: Rhinotermitidae). Ann. Entomol. Soc. Am. 99, 1028-1033. doi: 10.1603/0013-8746(2006)99[1028:ANKTPS]2.0.CO;2

Liu, X. J., Che, M., Xie, L., Zhan, S., Zhou, Z. H., Huang, Y. P., et al. (2016). Metatranscriptome of the protistan community in Reticulitermes flaviceps. Insect Sci. 23, 543-547. doi: 10.1111/1744-7917.12363

Lo Pinto, M., Varrica, G., and Agrò, A. (2016). Temporal variations in symbiotic hindgut protist community of the subterranean termite Reticulitermes lucifugus Rossi in Sicily. Insectes Soc. 63, 143-154. doi: 10.1007/s00040-015-0449-8

Lo, N., and Eggleton, P. (2011). "Termite phylogenetics and co-cladogenesis with symbionts," in Biology of Termites: A Modern Synthesis, eds D. E. Bignell, Y. Roisin, and N. Lo (London; New York, NY: Springer Science+Business Media BV), 27-50.

Mauldin, J. K. (1977). Cellulose catabolism and lipid synthesis by normally and abnormally faunated termites Reticulitermes flavipes. Insect Biochem. 7, 27-31. doi: 10.1016/0020-1790(77)90053-1

Mauldin, J. K., Carter, F. L., and Rich, N. M. (1981). Protozoan populations of Reticulitermes flavipes exposed to heartwood blocks of 21 American species. Mater. Org. 16, 15-28.

Mello, F. (1920). Considération sur les Trychonymphides de l'intestin de l'Archotermopsis wroughtoni Desn., étudiés par le Dr. A. Imms. Bull. Soc. Portu. Sci. Naturelles, 8, 189-198.

Ohkuma, M., and Brune, A. (2011). "Diversity, structure, and evolution of the termite gut microbial community," in Biology of Termites: A Modern Synthesis, eds D. E. Bignell, Y. Roisin, and N. Lo (New York City, NY: Springer), 413-438.

Otani, S., Mikaelyan, A., Nobre, T., Hansen, L. H., Koné, N. A., Sorensen, S. J., et al. (2014). Identifying the core gut microbiome of fungus-growing termites. Mol. Ecol. 23, 4631-4644. doi: 10.1111/mec.12874

Peterson, B. F., and Scharf, M. E. (2016). Metatranscriptome analysis reveals bacterial symbiont contributions to lower termite physiology and potential immune functions. BMC Genomics, 17:772. doi: 10.1186/s12864-016-3126-Z

Quast, C., Pruesse, E., Yilmaz, P., Gerken, J., Schweer, T., Yarza, P., et al. (2013). The SILVA ribosomal RNA gene database project: improved data processing and web-based tools. Nucleic Acids Res. 41, 590-596. doi: 10.1093/nar/gks1219

Ratnasingham, S., and Hebert, P. D. N. (2007). BARCODING, BOLD : the barcode of life data system (www.barcodinglife.org). Mol. Ecol. Notes 7, 355-364. doi: $10.1111 /$ j.1471-8286.2007.01678.x
Raychoudhury, R., Sen, R., Cal, Y., Sun, Y., Lietze, V. U., Boucias, D. G., et al. (2013). Comparative metatranscriptomic signatures of wood and paper feeding in the gut of termite Reticulitermes flavipes (Isoptera: Rhinotermitidae). Insect Mol. Biol. 22, 155-171. doi: 10.1111/imb. 12011

Scharf, M. E., Karl, Z., Sethi, A., and Boucias, D. G. (2011). Multiple levels of sinergistic collaboration in termite lignocellulose digestion. PloS ONE 6:e21709. doi: 10.1371/journal.pone.0021709

Stingl, U., and Brune, A. (2003). Phylogenetic diversity and whole-cell hybridization of oxymonad flagellates from the hindgut of the woodfeeding lower termite Reticulitermes flavipes. Protist 154, 147-155. doi: 10.1078/143446103764928530

Stingl, U., Radek, R., Yang, H., and Brune, A. (2005). The 'Endomicrobia': cytoplasmic symbionts of termite gut protozoa form a separate phylum of prokaryotes. Appl. Environ. Microbiol. 71, 1473-1479. doi: 10.1128/AEM.71.3.1473-1479.2005

Taerum, S. J., de Martini, F., Liebig, J., and Gile, G. H. (2018). Incomplete co-cladogenesis between Zootermopsis termites and their associated protists. Environ. Entomol. 47, 184-195. doi: 10.1093/ee/nvx193

Tamschick, S., and Radek, R. (2013). Colonization of termite hindgut walls by oxymonad flagellates and prokaryotes in Incisitermes tabogae, I. marginipennis and Reticulitermes flavipes. Eur. J. Protistol. 49, 1-14. doi: 10.1016/j.ejop.2012.06.002

Xie, L., Zhang, L., Zhong, Y., Liu, N., Long, Y., Wang, S., et al. (2012). Profiling the metatranscriptome of the protistan community in Coptotermes formosanus with emphasis on the lignocellulolyctic system. Genomics 99, 246-255. doi: 10.1016/j.ygeno.2012.01.009

Yamin, M. A. (1979). Flagellates of the orders Trichomonadida Kirby, Oxymonadida Grassé, and Hypermastigida Grassi \& Foà reported from lower termites (Isoptera families Mastotermitidae, Kalotermitidae, Hodotermitidae, Termopsidae, Rhinotermitidae, and Serritermitidae) and from the woodfeeding roach Cryptocercus (Dictyoptera: Cryptocercidae). Sociobiology 4, 5-119.

Conflict of Interest Statement: The authors declare that the research was conducted in the absence of any commercial or financial relationships that could be construed as a potential conflict of interest.

Copyright (c) 2018 Duarte, Nunes, Borges and Nobre. This is an open-access article distributed under the terms of the Creative Commons Attribution License (CC BY). The use, distribution or reproduction in other forums is permitted, provided the original author(s) and the copyright owner(s) are credited and that the original publication in this journal is cited, in accordance with accepted academic practice. No use, distribution or reproduction is permitted which does not comply with these terms. 